\title{
La Sección de Cartografía y Publicaciones del Instituto Geográfico y la introducción de las técnicas de reproducción fotomecánica (1904-1956) ${ }^{1}$
}

\author{
The Cartographic and Publications Section \\ of the Instituto Geográfico and the Introduction \\ of the Photomechanical Techniques of Reproduction \\ (1904-1956)
}

\author{
Francesc Nadal y Luis Urteaga*
}

Las dos primeras hojas del Mapa Topográfico de España a escala 1:50.000, la $\mathrm{n}^{\circ}$ 559: Madrid y la n ${ }^{\circ}$ 534: Colmenar Viejo, se editaron en 1875. Ambas hojas fueron bellamente estampadas a cinco colores y contienen una profusa información geográfica acerca de los usos del suelo. Unas características muy valiosas tanto desde el punto de vista cartográfico como del geográfico, pero que constituían una notable singularidad en relación a la mayor parte de los mapas topográficos nacionales publicados en Europa occidental durante el último tercio del siglo XIX.

\footnotetext{
${ }^{1}$ Este trabajo se ha realizado en el marco del proyecto de investigación CSO2011-C02-C01GEO, financiado por la Dirección General de Investigación y Gestión del Plan Nacional de $\mathrm{I}+\mathrm{D}+1$. Queremos agradecer la inestimable ayuda recibida por parte de Jesús Sastre Domingo del Instituto Geográfico Nacional.

* Francesc Nadal. Universitat de Barcelona (fnadal@ub.edu). Luis Urteaga. Universitat de Barcelona (urteaga@ub.edu).
} 
Durante este período los mapas topográficos nacionales de Francia, del Reino Unido, de Prusia, de Dinamarca, de Portugal, de Rusia y de Suecia se grababan en cobre, por lo que su impresión era monocroma (Nadal, Urteaga, 1990, 66-67). La estampación de un mapa a colores sólo podía realizarse entonces utilizando un sistema de reproducción cartográfico conocido como litografía o grabado en piedra, que era muy costoso tanto desde el punto de vista económico como del tiempo que había que destinar al grabado litográfico de cada hoja.

Por otro lado, una lectura atenta de la tabla de signos convencionales del Mapa Topográfico de España impresa en 1875 permite apreciar la exhaustiva información geográfica contenida en este mapa. La tabla contiene 150 signos y dieciséis tipos de letras diferentes, en los que, entre muchos otros elementos cartográficos y geográficos, se representan doce usos del suelo agrícola diferentes (árboles frutales, arrozales, olivares, viñedos, etc.). Esta abundancia de información geográfica contrasta mucho con la reproducida en algunos de los principales mapas topográficos nacionales de la época. Así, tanto la Carte d'État-Major au 1:80 000 del Service Géographique de l'Armée como el mapa topográfico de Inglaterra a escala 1:63.300 (one inch to the mile), que publicaba el Ordnance Survey, contienen una información geográfica notablemente inferior a la expuesta en el Mapa Topográfico de España (Nadal, Urteaga, 2012, 45).

Sin embargo, estas singularidades cartográficas y geográficas tan positivas dieron lugar a una serie de contrapartidas negativas desde el punto de vista editorial. Las tareas de dibujo, grabado e impresión de las hojas fueron, en un principio, muy lentas y costosas. Así, entre 1875 y 1914, tan sólo se estamparon mediante el sistema litográfico 143 de las 1.106 hojas que componían la primera edición del Mapa Topográfico de España; es decir únicamente el 13 por ciento del total de las hojas (véase figura 1). Unas cifras que indican que el ritmo de edición fue, durante los 39 años que estuvo vigente este sistema de reproducción cartográfica, de 3,6 hojas impresas por año. Un ritmo exasperantemente lento, ya que si no se hubiese cambiado el sistema de reproducción litográfico, habría sido necesario invertir 307 años para completar la primera edición del Mapa Topográfico de España.

Las páginas siguientes están dedicadas a explicar las medidas adoptadas, a principios de siglo xx, por los responsables del Instituto Geográfico para resolver este grave problema editorial. Unas medidas que comportaron el cambio de un sistema de reproducción cartográfica, el litográfico, por otro, el fotomecánico. El objetivo de este trabajo es explicar justamente cómo este nuevo sistema acabó por convertirse en el procedimiento técnico con el qué se imprimió la mayor parte de la primera edición del Mapa Topográfico de España a escala 1:50.000. 
FIGURA 1

EVOLUCIÓN DE LA PRIMERA EDICIÓN DEL MAPA TOPOGRÁFICO DE ESPAÑA A ESCALA 1:50.000 (1875-1968)

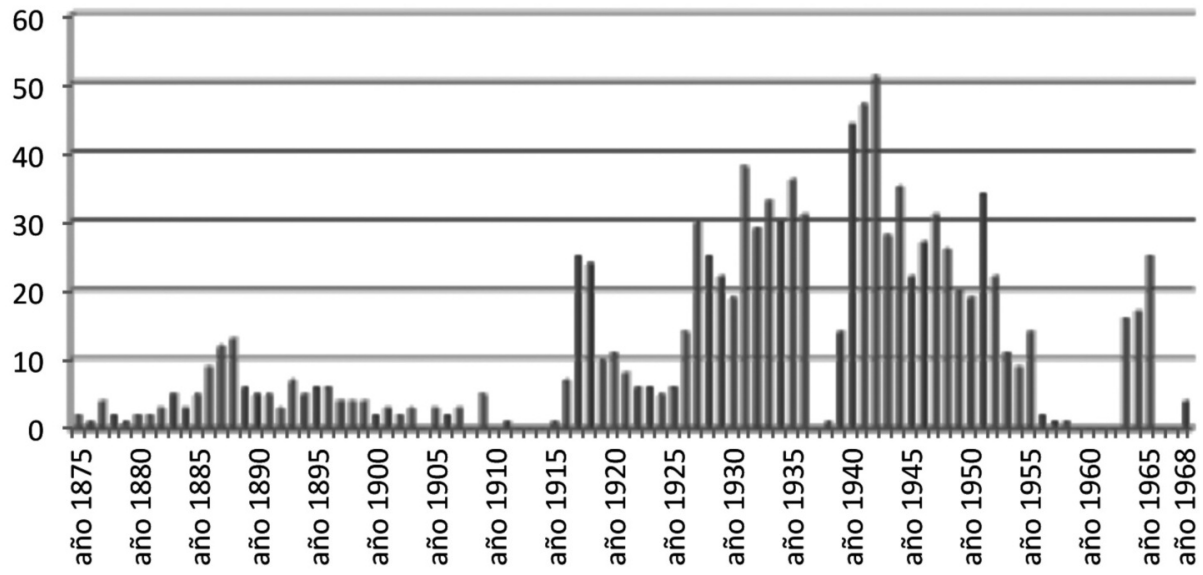

Fuente: elaboración propia a partir de Urteaga, Nadal, 2001.

A fin de explicar tanto este proceso de cambio tecnológico como sus resultados, se ha dividido el presente trabajo en tres apartados diferentes. En el primero se explican las transformaciones de tipo organizativo, humano y material que tuvieron lugar a raíz de la introducción e implantación del nuevo sistema de reproducción cartográfica. En el segundo, se tratan, de forma general, las principales características de las dos primeras técnicas de reproducción fotomecánicas adoptadas: la del heliograbado en cobre y la del fotolitografiado en zinc. Y, en el tercero, se aborda la evolución que experimentó la primera edición del Mapa Topográfico de España desde la primera hoja estampada en 1915 con la primera de estas técnicas hasta su sustitución, a mediados de la década de 1950, por una nueva técnica de reproducción fotomecánica: el esgrafiado en vidrio. Cierran el trabajo un apartado de conclusiones y otro de fuentes y bibliografía.

\section{La Sección de Cartografía y Publicaciones (1904-1956)}

En 1904 el director del Instituto Geográfico, el coronel de artillería Francisco Martín Sánchez, preocupado por la lentitud con que avanzaba la edición 
del Mapa Topográfico de España, comisionó a dos ingenieros geógrafos, Luis Cubillo Muro y José Galbis Rodríguez, para que realizasen un viaje de estudio por diferentes ciudades europeas a fin de conocer los métodos de grabado e impresión utilizados en algunos de los principales centros cartográficos europeos. El resultado de sus indagaciones quedó expuesto en una memoria que ambos ingenieros geógrafos redactaron en $1905^{2}$. En la misma se defendía, entre otras recomendaciones, la implantación de un sistema de reproducción cartográfica denominado heliograbado en cobre tal como se venía aplicando en el K.u.K. Militär-Geographisches Institut de Viena desde principios de la década de 1870 (Koeman, 1972, 149).

La propuesta prosperó. Sin embargo, para poder aplicarla de forma eficiente fue preciso realizar múltiples cambios de tipo organizativo, humano y material. En este sentido, es preciso tener en cuenta que, en 1904, el Instituto Geográfico contaba, según el reglamento aprobado el ocho de julio de ese año, con un Negociado de Publicaciones, al que estaban adscritos dos tipos de personal técnico diferentes: los grabadores y el Cuerpo Auxiliar de Delineantes, formado por 14 miembros $^{3}$. Ese mismo año se creó, además, en el seno de este negociado una Sección de Dibujo y Cálculo Planimétrico ${ }^{4}$.

Este negociado, organizado en función del sistema litográfico, experimentaría muy pronto grandes transformaciones como consecuencia de la introducción de las nuevas técnicas del heliograbado en cobre. Así, en 1907, gracias a la citada memoria presentada por Luis Murillo y José Galbis y a las gestiones del entonces director general del Instituto Geográfico, el coronel de Artillería Francisco Martín Sánchez, se consiguió un crédito extraordinario de 21.875 pesetas para organizar un taller de heliograbado ${ }^{5}$. Al año siguiente, una vez instalado dicho taller, se efectuaron las primeras pruebas de estampación de mapas realizadas mediante el sistema de reproducción fotomecánica ${ }^{6}$.

Por otro lado, durante los años de implantación del heliograbado en cobre, el Instituto Geográfico tuvo que irse adaptando a nuevas innovaciones. Así, en 1910, el K.u.K. Militär-Geographische Institut de Viena había introducido, por

${ }^{2}$ L. Cubillo Muro y J. Galbis Rodríguez (1905): Memoria referente a los procedimientos de fotograbado convenientes a las publicaciones del Instituto, Madrid, [s.n.], 25 folios., ms. (Archivo del Instituto Geográfico Nacional).

${ }^{3}$ Gaceta de Madrid, 1904, no 205.

${ }^{4}$ Instituto Geográfico y Estadístico, 1914: 15.

${ }^{5}$ Gaceta de Madrid, 1907, n 203. Martín Sánchez, 1908: 50.

${ }^{6}$ Instituto Geográfico y Estadístico, 1914: 16. 
primera vez, en Europa una máquina de imprimir ófset, que tenía una capacidad de impresión cuatro veces superior a la de las máquinas existentes hasta entonces (Kretschmer, 1997, 151). Como consecuencia de ello, el Instituto Geográfico organizó talleres específicos de fotografía, metalografía y calcografía, al tiempo que adquirió dos máquinas planas Albert, una rotativa Offset y dos minervas Victoria ${ }^{7}$.

El principal artífice de este proceso de cambio tecnológico fue el ingeniero geógrafo Luis Cubillo Muro (Madrid, 1864-1925). Cubillo, que era ingeniero de minas, había ingresado en 1896 en el Cuerpo de Geodestas y, en 1900, en el recién creado Cuerpo de Ingenieros Geógrafos (Ruiz Morales, 2003, 149). Unos años más tarde, en 1906, redactó con el ingeniero geógrafo Aurelio Capilla del Valle una detallada «Memoria relativa a la formación del Mapa Especial Magnético de España» (Anduaga, 2009, 93).

A principios de la década de 1910 Cubillo era ya el jefe del Negociado de Publicaciones. Durante los años que estuvo al frente del mismo, realizó esfuerzos considerables a fin de hacer realidad la implantación del nuevo sistema de reproducción cartográfica. Una tarea que no resultó nada fácil. Así, a fin de vencer las múltiples resistencias que encontró, decidió aprender el funcionamiento de las nuevas técnicas de reproducción fotomecánica, llevando a cabo prácticas en diversos talleres de edición. Además, para la aplicación de estas técnicas diseñó un «portaplanos» y un «portaoriginales» (Espasa, 1913, vol. 16; Martín López, 2001, 87). Por otro lado, envió a algunos de sus operarios a Viena, París, Berna y Londres con el propósito de que aprendiesen las nuevas técnicas de reproducción gráfica. Unos años más tarde, en 1921, a raíz de un viaje de estudio que realizó a Berna redactó una detallada memoria titulada «Cartografía y talleres de reproducción [del] Servicio Topográfico Federal, Suiza» ${ }^{8}$. Después, el 18 de enero de 1924, dejo la dirección del Negociado de Publicaciones al ser nombrado, por su pariente el general Miguel Primo de Rivera, director general del Instituto Geográfico (Galbis, 1950, 111).

El Reglamento del Instituto Geográfico aprobado el 22 de diciembre de 1911 mantenía la existencia del Negociado de Publicaciones, así como la del Cuerpo Auxiliar de Delineantes. Sin embargo, un capítulo del mismo estaba ya dedicado íntegramente a enumerar el personal empleado en los diversos talleres y áreas de trabajo de la Sección de Artes Gráficas. Así, el taller de gra-

${ }^{7}$ Idem.

${ }^{8}$ L. Cubillo Muro (1921): Cartografía y talleres de reproducción [del] Servicio Topográfico Federal, Suiza, Berna. Madrid, [s.n.], 62 fol. Mecanografiados + 24 láminas (Instituto Geográfico Nacional). 
bado estaba formado por un profesor jefe, por grabadores en piedra y en metal y por aspirantes. Por su parte, el taller de litografía estaba compuesto por un litógrafo regente, por calcógrafos estampadores en cobre, litógrafos reportistas, ayudantes de estampación y maquinistas-litógrafos. Por otro lado, se indica ya la existencia de un grupo de fotógrafos y heliograbadores que, de momento, no disponían de taller propio. Y, por último, se señala que la imprenta contaba con un regente, tipógrafos y maquinistas impresores ${ }^{9}$.

Dos años más tarde, en 1913, el Negociado de Publicaciones se encontraba organizado ya en tres secciones: la de Dibujo y Cálculo Planimétrico, la de Cartografía y la de Artes Gráficas. La primera sección, la de Dibujo y Cálculo Planimétrico, estaba encargada de suministrar al negociado y al Ministerio de Hacienda copias de las planimetrías de los términos municipales. Entre sus cometidos también estaba el cálculo de las superficies de los perímetros de los polígonos planimétricos ${ }^{10}$. Al frente de esta sección había un ingeniero geógrafo y dos topógrafos. Formaban parte de la misma, además, la mayoría de miembros del Cuerpo Auxiliar de Delineantes, formado entonces por 31 miembros, 25 de los cuales eran delineantes y seis ayudantes calculadores ${ }^{11}$. La segunda sección, la de Cartografía, fue creada el 14 de diciembre de 1912 y se ocupaba del trazado de proyecciones y del diseño y dibujo de originales tanto del Mapa Topográfico de España como de los diversos mapas que editaba el Instituto Geográfico. El personal adscrito a la misma estaba compuesto por un ingeniero geógrafo y por diversos topógrafos.

La tercera sección, la de Artes Gráficas, había sido reorganizada hacía muy poco tiempo y agrupaba los antiguos servicios de grabado litográfico e impresión tipográfica, así como los nuevos de reproducción fotomecánica. Esta sección estaba dividida, a su vez, en tres talleres diferentes: el de grabado, el de litografía y el de reproducciones fotomecánicas. El primer taller estaba integrado por un grabador primero o topógrafo, tres grabadores segundos, un grabador en cobre y un aspirante. El segundo taller estaba formado por cinco litógrafos y cinco ayudantes de estampación. Mientras que el tercer taller estaba constituido por un fotógrafo operador, un fotograbador, un ayudante de fotógrafo y un heliograbador ${ }^{12}$. Algunas de las hojas del Mapa Topográfico de España que se editaron entre 1909 y 1911, como la no 1005: Osuna (1911), llevan impresa en la parte central del margen inferior de las mismas la si-

\footnotetext{
${ }^{9}$ Gaceta de Madrid, 1911, n 362.

${ }^{10}$ Instituto Geográfico y Estadístico, 1914: 15.

11 Ibidem: 31.
} 
guiente información: «Sección de Artes Gráficas del Instituto Geográfico y Estadístico. F. Noriega, R. Marín y M. Díaz dibujaron».

En 1918, la Sección de Artes Gráficas agrupaba un total de 24 miembros. En el primer taller, el de reproducciones fotomecánicas, estaban empleados dos fotógrafos, un fotograbador, un heliograbador y dos ayudantes. En el segundo taller, el de grabado, trabajaban cinco grabadores y dos aspirantes. Y, en el tercero, el de calcografía y litografía, había empleados cuatro litógrafos, un calcógrafo estampador, un marcador y cinco ayudantes ${ }^{13}$. Ese año el Negociado de Publicaciones todavía contaba con un único cuerpo técnico: el Auxiliar de Delineantes, integrado por 46 miembros $^{14}$. Sin embargo, esta situación cambió en 1922 a raíz de la aprobación de la Ley de presupuestos para el año 1922-23, que posibilitó la creación de otros dos cuerpos técnicos: el de Oficiales de Artes Gráficas y el de Ayudantes de Artes Gráficas ${ }^{15}$. El primero de ambos cuerpos fue creado por una Real Orden de 12 de agosto de 1922, mientras que el segundo lo fue por otra Real Orden aprobada seis días más tarde ${ }^{16}$. Por su parte, el Cuerpo Auxiliar de Delineantes terminó convirtiéndose, durante la década de 1920, en el Cuerpo de Delineantes Cartográficos.

A mediados de esa década el Negociado de Publicaciones y Cartografía experimentó nuevas e importantes transformaciones. En primer lugar se produjo la adopción de una nueva técnica de reproducción fotomecánica: la fotolitografía en zinc. Este cambio afectó tanto a la composición del personal técnico como a la maquinaria necesaria para su funcionamiento. Como consecuencia de ello, a partir de 1926 en los concursos públicos de plazas del Cuerpo de Oficiales de Artes Gráficas apareció una nueva figura técnica, la del litógrafo maquinista-reportista, al tiempo que desaparecía la del heliograbador. Así, entre 1926 y 1927, el Instituto Geográfico sacó a concurso seis plazas de litógrafos maquinistas-reportistas para formar parte de dicho cuerpo ${ }^{17}$. Los concursantes tenían que demostrar para obtener dichas plazas que eran capaces de efectuar un «reporte sobre zinc para máquinas Offset de cinco planchas fotomicrográficas de una hoja del Mapa Topográfico Nacional ${ }_{\gg}{ }^{18}$.

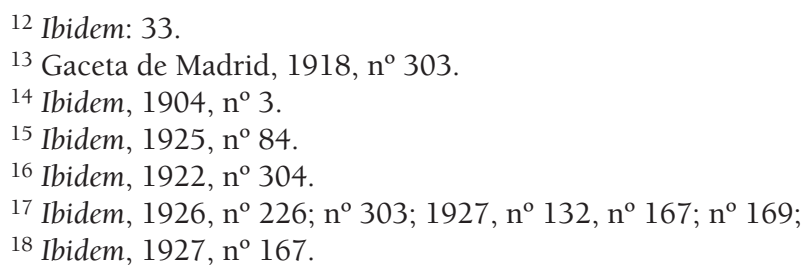


Por otro lado, en octubre de 1929, en el marco del proceso de adopción de esta nueva técnica, el gobierno aprobó destinar una partida de 70.720 pesetas a adquirir una máquina litográfica Offset Rolland ${ }^{19}$. La estrecha relación que se produjo, durante el primer tercio del siglo xx, entre la técnica de la fotolitografía y el desarrollo de las rotativas Offset fue el factor determinante que impulsó la difusión de esta técnica de reproducción fotomecánica (Cook, 2002, 150). Además de esta relación, existen otros dos factores que también contribuyeron al éxito de la fotolitografía en zinc: su aplicación simplificó las tareas de impresión y posibilitó la realización de tiradas de mapas en color superiores a las de las otras técnicas de reproducción cartográficas existentes (Cook, $2002,150)$. Como consecuencia de ello, el uso de la fotolitografía en zinc en los principales centros cartográficos europeos se generalizó durante el quinquenio 1925-1930, justo durante los años en que el Instituto Geográfico llevó a cabo su implantación (Koeman, 1971, 151; Heras, 2009, 66).

Los cambios no terminaron aquí. Durante muchos años la falta de espacio de los diversos talleres de la Sección de Artes Gráficas incidió, de forma negativa, en el rendimiento de las nuevas técnicas de reproducción fotomecánica. En un informe elaborado en 1913 por la Dirección General del Instituto Geográfico se señalaba que, debido a:

la falta de local (...) y aun cuando los obreros de la sección tienen los conocimientos y la práctica necesarios, no es posible conseguir el desarrollo que debieran tener nuestros talleres ni poner en práctica algunos procedimientos modernos y otros talleres muy precisos como la Galvanoplastia, la Esterotipia y la Encuadernación ${ }^{20}$.

De hecho, hubo que esperar a mediados de la década de 1920 para que se pusiese solución a este problema. Esta se hizo realidad, el nueve de julio de 1926, con la aprobación de un Real Decreto de Obras y Servicios del Estado, en el que se consignaba una partida de 4.360 .183 pesetas para la construcción, durante el cuatrienio 1926-1929, de un edificio destinado a los Talleres del Instituto Geográfico ${ }^{21}$. Dos años más tarde, el nueve de septiembre de 1928, se autorizó a la Dirección General del Instituto Geográfico a realizar una serie de obras suplementarias de instalación de rejas y cubiertas de cristales en dicho edificio en construcción por valor de 85.740 pesetas $^{22}$. Dos meses más tarde, el uno de noviembre de ese año, se aprobó otra partida, esta vez de

\footnotetext{
${ }^{19}$ Ibidem, 1929, nº 274.

${ }^{20}$ Instituto Geográfico y Estadístico, 1914: 16.

${ }^{21}$ Gaceta de Madrid, 1926, $\mathrm{n}^{\circ} 197$.

22 Ibidem, 1928, n 277.
} 
202.473 pesetas, para elevar un piso más del citado edifico en construcción ${ }^{23}$. $\mathrm{Y}$, cuatro años más tarde, se emprendieron nuevas obras de ampliación. Así, el 24 de diciembre de 1932, se aprobó una partida de 212.035 pesetas para la construcción de dos naves de ampliación de los Talleres del Instituto Geográfico $^{24}$. En total, entre julio de 1926 y diciembre de 1932, se habían presupuestado inversiones por valor de 4.860 .431 pesetas para la construcción y ampliación del edificio de los Talleres del Instituto Geográfico (figura 2).

\section{FIGURA 2}

PLANO DEL RECINTO Y EMPLAZAMIENTO DE LOS EDIFICIOS QUE CONSTITUÍAN EL INSTITUTO GEOGRÁFICO EN 1940, LEVANTADO POR LOS ARQUITECTOS LORENZO ORTIZ IRIBAS Y ANTONIO RUBIO MARÍN. EL EDIFICIO SITUADO EN LA PARTE INFERIOR DEL PLANO ES EL DEDICADO A LOS TALLERES DEL INSTITUTO GEOGRÁFICO

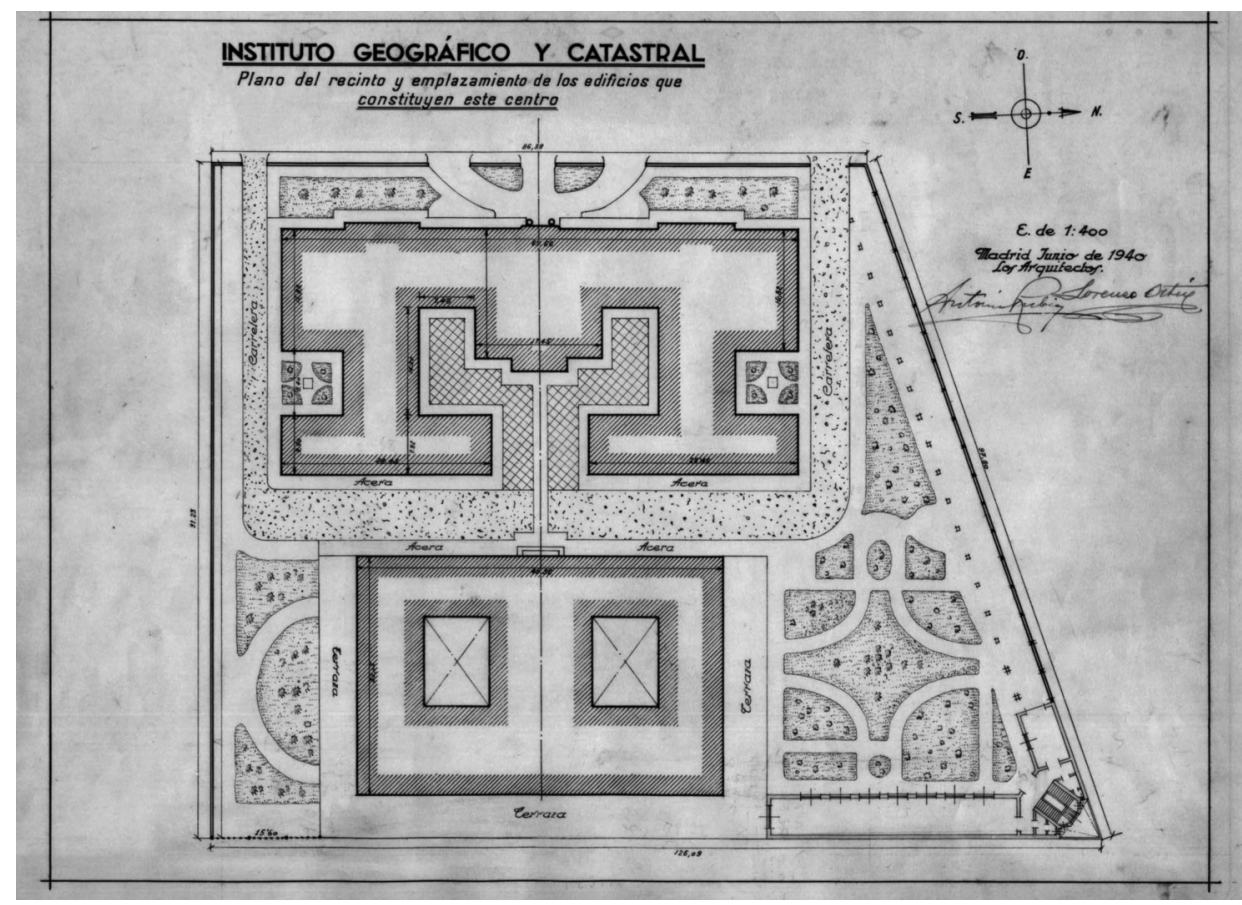

Fuente: Instituto Geográfico Nacional.

${ }^{23}$ Ibidem, 1928, n 835 .

${ }^{24}$ Ibidem, 1932, n 312. 
El siete de marzo de 1926, el Negociado de Publicaciones quedó adscrito a la Sección Primera del Instituto Geográfico y Catastral relativa al Mapa Topográfico de España y a los trabajos topográficos del catastro, pasando a denominarse Negociado de Publicaciones y Cartografía ${ }^{25}$. Unos días más tarde, el 18 de marzo, se nombró al ingeniero geógrafo Eduardo Martínez y Berrueco (Puebla de Montalbán, 1860-?) primer jefe de este negociado. Martínez y Berrueco, que había ingresado en 1883 en el cuerpo de topógrafos y en 1900 en el nuevo cuerpo de Ingenieros Geógrafos permaneció al frente del mismo hasta principios de agosto de $1928^{26}$. Precisamente, fue durante el tiempo que Martínez y Berrueco estuvo al frente de este negociado cuando se llevaría a cabo la introducción de la fotolitografía en zinc.

El siguiente responsable del negociado fue Lorenzo Ortiz e Iribas (Estella, 1884-Madrid, 1947) (figura 3). Ortiz, que había obtenido el título de arquitecto por la Escuela Especial de Arquitectura de Madrid en 1906 y el de licenciado en ciencias por la Universidad Central de Madrid en 1907, ingresó este año en el Cuerpo de Ingenieros Geógrafos. Desde entonces hasta 1919 estuvo destinado a diferentes brigadas topográficas (Zamora, Zaragoza y Madrid). Pero, a partir de este año se incorporó al Negociado de Geodesia, llevando a cabo trabajos en diferentes brigadas geodésicas. Más tarde, en septiembre de 1925, fue destinado al Negociado de Archivos, cargo en el que permaneció hasta enero de 1926, en que fue nombrado segundo jefe del Negociado de Publicaciones y Cartografía ${ }^{27}$. Después, en febrero de 1933, fue nombrado jefe de los trabajos del plano de la ciudad de Salamanca, cargo que no le impidió continuar al frente del Servicio de Publicaciones y Cartografía.

En agosto de 1928, Lorenzo Ortiz tenía a sus órdenes cuatro ingenieros geógrafos. El primero de ellos, Antonio Rubio y Marín (Granada, 1883-Madrid, 1980) era arquitecto y había ingresado en el Cuerpo de Ingenieros Geógrafos en 1909. Rubio compaginó sus obligaciones como ingeniero geógrafo con una notable actividad como arquitecto, siendo autor, entre otras obras, del edificio de Correos de Zaragoza (1926), del mercado de abastos de Don Benito (1931), del edificio neobarroco de la Unión Musical de Madrid situado en la carrera de San Jerónimo, así como de diversos edificios de viviendas de Madrid (Sanz, 2010, 198).

\footnotetext{
25 Ibidem, 1926, nº 66.

${ }^{26}$ Instituto Geográfico Nacional, Expediente personal $n^{\circ} 919$.

27 Ibidem n ${ }^{\circ} 2.630$.
} 


\section{FIGURA 3}

\section{CARNET DE TRABAJO DEL INSTITUTO GEOGRÁFICO Y ESTADÍSTICO DE LORENZO ORTIZ E IRIBAS}

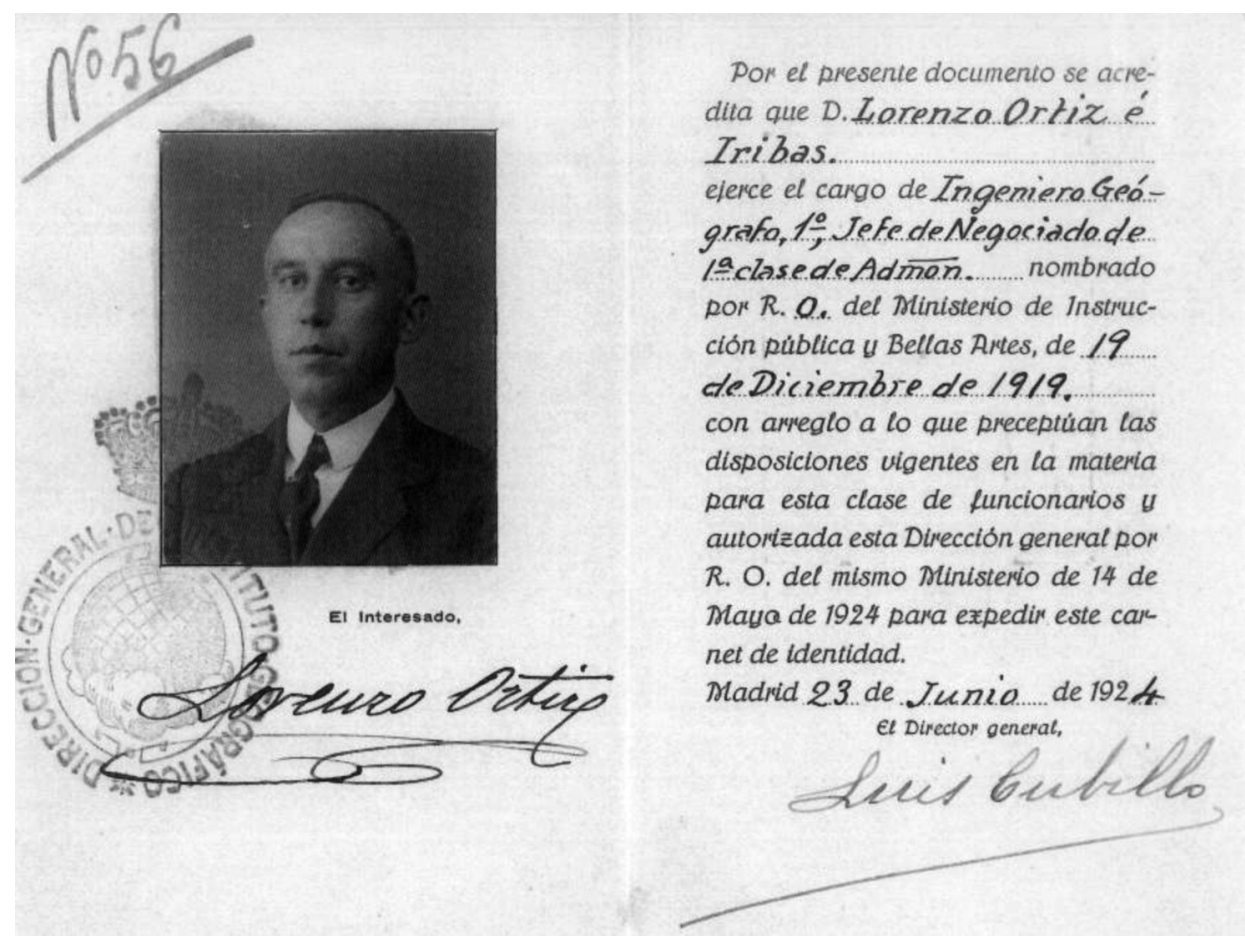

Fuente: Instituto Geográfico Nacional.

El segundo ingeniero geógrafo, José $\mathrm{M}^{a}$ Cobos y Álvarez (Calatayud, 1880-?), era ingeniero industrial, licenciado en ciencias y formaba parte del Cuerpo de Ingenieros Geógrafos desde mayo de 1907. En 1929 era el jefe de la brigada de campo adscrita al Negociado de Publicaciones y Cartografía y dedicada a las tareas de realizar las últimas comprobaciones sobre el terreno de las hojas del Mapa Topográfico de España que estaban en proceso de edición. Sin embargo, en mayo de ese año, dejó de formar parte de este negociado, siendo sustituido en la jefatura de esta brigada de campo por el ingeniero geógrafo Manuel Chueca Martínez (1893-?). Chueca, que era ingeniero militar de formación, había ingresado en el Cuerpo de Ingenieros Geógrafos en octubre de 1920. 
Tras llevar a cabo múltiples labores de carácter topográfico y geodésico, en junio de 1928, se integró en el Negociado de Publicaciones y Cartografía, pasando a dirigir, en mayo del año siguiente, la brigada de campo adscrita al mismo. Mientras que el cuarto geógrafo, Antonio Revenga Carbonell (Valencia, 1888-Madrid, 1975) era doctor en ciencias por la Universidad Central de Madrid y, en marzo de 1912, había ingresado en el Cuerpo de Ingenieros Geógrafos. Sus preocupaciones por las técnicas de reproducción fotomecánica le llevaron a traducir una serie de obras del químico y fotógrafo italiano Rodolfo Namias (1867-1938) ${ }^{28}$. En junio de 1928 se encontraba destinado al Negociado de Cartografía y Publicaciones como jefe de los Talleres del Instituto Geográfico, cargo que mantuvo, como mínimo, hasta $1935^{29}$.

El Negociado de Publicaciones y Cartografía contaba, además en 1928, con otros 123 empleados, de los que 58 eran miembros del Cuerpo de Delineantes Cartográficos, 44 del de Oficiales de Artes Gráficas y 21 del de Ayudantes de Artes Gráficas ${ }^{30}$. De hecho, el incremento progresivo de personal que se produjo en este negociado, entre 1918 y 1928, había duplicado el número de empleados dedicados a las tareas de dibujo, grabado e impresión de las hojas del Mapa Topográfico de España (véase cuadro 1).

Este extraordinario crecimiento quedó paralizado tras el advenimiento de la Segunda República en 1931 (Nadal, Urteaga, 2013, 45-66). Una de las primeras medidas adoptadas por el nuevo gobierno republicano fue, precisamente, la aprobación, el 28 de octubre de 1931, de un decreto de amortización de las plantillas del Instituto Geográfico por el que las relativas a los cuerpos de delineantes cartográficos, oficiales de artes gráficas y ayudantes de artes gráficas quedaban prácticamente congeladas. Esta era una medida enmarcada en el contexto de la grave situación económica por la que estaba atravesando el país a raíz de la gran crisis económica de 1929 y con la que se pretendía, de acuerdo con los criterios liberales de política económica predominantes entonces, contener el gasto público a fin de mantener unos presupuestos del Estado equilibrados (Martínez, 2000, 583). La política de congelación de plantillas se vio agravada en agosto de 1935, cuando se aprobó una Ley de res-

${ }^{28}$ Entre estas traducciones es preciso reseñar las siguientes: Procedimientos de ilustración gráfica: fotograbado, fototipia, fotolitografía, heliograbado, rotocalcografía (1920); Manual teórico-práctico de química fotográfica (1924); y, La fotografía en colores: la autocromía y procedimientos con placas de mosaico en general; la tricomía fotográfica y fotomecánica, diversos procedimientos para las fotografías en colores (1925).

${ }^{29}$ Gaceta de Madrid, 1928, $\mathrm{n}^{\circ} 172$.

30 Ibidem, nº 277. 
CUADRO 1.

EVOLUCIÓN DE LAS PLANTILLAS DE LOS CUERPOS TÉCNICOS ADSCRITOS A LA SECCIÓN DE CARTOGRAFÍA Y PUBLICACIONES ENTRE 1913 Y 1944

\begin{tabular}{lcccccc}
\hline \multicolumn{1}{c}{ Cuerpos técnicos } & 1913 & 1918 & 1928 & 1935 & 1936 & 1944 \\
\hline delineantes cartográficos & 31 & 46 & 58 & 43 & 37 & 37 \\
oficiales de artes gráficas & 20 & 24 & 44 & 51 & 45 & 43 \\
ayudantes de artes gráficas & & & 21 & 27 & 25 & 23 \\
\hline Total & 51 & 70 & 123 & 121 & 107 & 103 \\
\hline
\end{tabular}

Fuente: elaboración propia a partir de Instituto Geográfico, 1914; Gaceta de Madrid, 1918, n 302; 1928, n 277; 1935, nº 38; y, Ministerio de Instrucción Pública, junio de1936.

tricciones de gastos del Estado, que provocó una reducción en el número de miembros de los cuerpos técnicos del Instituto Geográfico. Esta política de recortes no se detuvo, sin embargo, aquí, ya que durante el breve espacio de tiempo en que gobernó el Frente Popular se produjeron nuevas reducciones de personal (véase cuadro 1$)^{31}$.

Como consecuencia de ello, entre 1928 y 1936, los cuerpos técnicos adscritos al Negociado de Publicaciones y Cartografía, que en 1935 había pasado a denominarse Servicio de Publicaciones y Cartografía, habían perdido 16 miembros. Ahora bien, esta reducción no afectó a todos los cuerpos por igual. Así, el de Delineantes Cartográficos resultó, tal como puede apreciarse en el cuadro 1, el más perjudicado, ya que perdió 21 miembros. Por su parte, el de Oficiales de Artes Gráficas permaneció prácticamente igual, tras haber experimentado un importante crecimiento durante esos años. Mientras que el de Ayudantes de Artes Gráficas experimentó, por el contrario, un pequeño aumento de cuatro miembros.

${ }^{31}$ Dirección General del Instituto Geográfico (1935): Distribución del personal. Año de 1935, Madrid, texto mecanografiado (Archivo del Instituto Geográfico Nacional); Ministerio de Instrucción Pública y Bellas Artes (1936): Relación nominal del personal de todos los cuerpos que integran el Instituto Geográfico, con expresión de los servicios y negociados donde presta servicio, incluyendo el Servicio de Catastro Topográfico Parcelario, dependiente de la Dirección General de Propiedades y Contribución Territorial. 16 de junio de 1936, Madrid, [s.n.] 26 pp. mecanografiadas (Archivo del Instituto Geográfico Nacional, caja 103). 
El estallido de la Guerra Civil provocó una serie de cambios en la organización del Servicio de Publicaciones y Cartografía. Durante las primeras semanas del conflicto, Lorenzo Ortiz permaneció al frente del mismo, realizando diversas gestiones para el gobierno republicano. Sin embargo, sus desavenencias con el mismo hicieron que fuese apartado de su cargo durante el mes de agosto de 1936. En 1937 se encontraba ya integrado en la nueva Administración franquista. Los otros ingenieros geógrafos adscritos a este servicio antes de la guerra, Antonio Rubio Marín, Manuel Chueca Martínez y Antonio Revenga Carbonell, siguieron una trayectoria similar.

Por otro lado, en una circular emitida en enero de 1937 se indica la existencia de dos unidades técnicas diferentes: la de Publicaciones y la de Cartografía y Delineación. Al frente de la primera se encontraba el ingeniero geógrafo Gregorio Uriarte Martínez, mientras que al frente de la segunda se encontraba, en la sede de Madrid, el ingeniero geógrafo Alonso Álvarez Martínez y, en la sede de Valencia, donde se hallaba entonces el gobierno de la República, el ingeniero geógrafo Santos Anadón Laplaza (Heras, 2009, 121; Burgueño, 2010, 274).

El gobierno de Burgos decidió, por su parte, el 22 de febrero de 1938, que las actividades del Servicio Nacional del Instituto Geográfico y Estadístico quedaran organizadas en diversas secciones, una de las cuales, la quinta, estaba encargada de las labores de cartografía, publicaciones, artes gráficas y talleres ${ }^{32}$. A los pocos días de haberse producido esta reorganización, en marzo de 1938, se nombró a Lorenzo Ortiz e Iribas jefe de esta sección, cargo que mantuvo hasta enero de 1942. A continuación, su lugar fue ocupado por el ingeniero geógrafo que había sido su mano derecha: Antonio Rubio Marín 33 .

Dos años más tarde, el 22 de enero de 1944, se aprobó un nuevo reglamento del Instituto Geográfico y Catastral, por el que la quinta sección pasó a denominarse Sección de Cartografía y Publicaciones ${ }^{34}$. Este reglamento conservaba los mismos cuerpos técnicos que existían antes del estallido de la gue$\mathrm{rra}^{35}$. Por otro lado, la Ley de 31 de diciembre de 1946 relativa a la modificación de plantillas de diversos cuerpos del Instituto Geográfico establecía que el Cuerpo de Delineantes Cartográficos debía estar formado por 37 miembros, el de Oficiales de Artes Gráficas por 43 y el de Ayudantes de Artes Gráficas por 23 (véase cuadro 1). Unas cifras que, si bien eran prácticamente

\footnotetext{
32 Boletín Oficial del Estado, 1938, nº 492.

33 Instituto Geográfico Nacional, Expediente personal no 2.630 .

${ }^{34}$ Boletín Oficial del Estado, 1944, n 27.

${ }^{35} \mathrm{Idem}$.
} 
idénticas a las existentes en junio de 1936 no deben hacernos olvidar que, durante los primeros años de la postguerra, algunos de los miembros de dichos cuerpos que, durante la contienda, habían colaborado, de forma activa, con el gobierno republicano fueron objeto de duras condenas de prisión o bien dados de baja del Instituto Geográfico.

Este fue el caso del ingeniero geógrafo Santos Anadón Laplaza, que fue condenado, el 5 de mayo de 1941, a doce años y medio de reclusión menor ${ }^{36}$. Así como el de los oficiales de artes gráficas Agapito Pérez Cortina, que fue condenado a 30 de reclusión mayor, y José Fernández Díaz, que fue condenado a 12 años y un día de reclusión ${ }^{37}$. Por su parte, los oficiales de artes gráficas Félix Cándido Pérez Orte, Manuel Fernández-Sánchez Garrido y Cayetano Redondo Aceña fueron dados de baja de su servicio en el Instituto Geográfico ${ }^{38}$.

A fin de sustituir estas bajas y estabilizar las plantillas de estos cuerpos técnicos, entre 1942 y 1944, se convocaron 24 plazas del Cuerpo de Oficiales de Artes Gráficas, 16 del de Ayudantes de Artes Gráficas y 8 del de Delineantes Cartográficos ${ }^{39}$. El esfuerzo realizado para restablecer y mejorar la capacidad productiva de la Sección de Cartografía y Publicaciones no se detuvo aquí. Así, el nueve de noviembre de 1954, se aprobó una orden por la que se destinaba una partida de 2.481 .954 pesetas a la construcción de un pabellón dedicado a la ampliación de los servicios de esta sección ${ }^{40}$. El proyecto arquitectónico fue encargado al arquitecto Antonio Rubio Marín que, entre 1949 y 1953, había sido el presidente del Colegio Oficial de Arquitectos de Madrid y que, desde 1953, había dejado la dirección de la Sección de Cartografía y Publicaciones. Su cargo fue ocupado, a partir de entonces, por el ingeniero geógrafo e ingeniero industrial Bernardo Costilla y Piñal (1892-1980), quien tenía a sus órdenes como jefe de talleres de la Sección de Artes Gráficas al ingeniero geógrafo y oficial de la Armada Ildefonso Nadal Romero (1916-2000).

\footnotetext{
${ }^{36}$ Ibidem, 1941, $\mathrm{n}^{\circ} 111$.

37 Ibidem, $\mathrm{n}^{\circ} 362 ; 1943, \mathrm{n}^{\circ} 222$

38 Ibidem, 1939, $\mathrm{n}^{\circ} 203$.

${ }^{39}$ Ibidem, 1942, no 9, no $152 ; 1943, n^{\circ} 168, n^{\circ}{ }^{\circ} 170 ; 1944, n^{\circ} 119, n^{\circ} 339, n^{\circ} 362$.

40 Ibidem, 1954, no 317 y no 322.
} 


\section{LAS TÉCNICAS DE REPRODUCCIÓN FOTOMECÁNICA}

El gran desarrollo que experimentó la fotografía durante la primera mitad del siglo XIX dio lugar a que, entre 1820 y 1830, se realizaran las primeras tentativas de aplicación de diversas técnicas fotomecánicas a la reproducción cartográfica. Hubo que esperar, sin embargo, al último tercio del siglo XIX y principios del siglo xx para que su uso se empezase a generalizar entre los grandes centros cartográficos europeos (Koeman, 1972; 137-155; Wallis, Robinson, 1987, 303-307; Cook, 2002, 138). Los primeros pasos dados por el Instituto Geográfico para adoptarlas tuvieron lugar, tal como ya se ha señalado, en 1904. Como resultado de ello, en 1915, empezaron a publicarse las primeras hojas con una de las principales técnicas de reproducción fotomecánica vigentes entonces: el heliograbado en cobre. Esta técnica se aplicó hasta 1926, año en que se implantó la fotolitografía en zinc.

La palabra «heliograbado» constituye una acepción culta del término «fotograbado»; es decir de un procedimiento empleado para grabar materiales sensibles a la luz a fin de conseguir una matriz o plancha, que permita su reproducción. El heliograbado era, tal como se ha señalado, un sistema de reproducción fotomecánica que se venía empleando con éxito en el K.u.K. Militär-Geographische Institut de Viena desde 1875, cuando el pintor, fotógrafo e ilustrador checo Karel Václav Kli (1841-1926) llevó a cabo las primeras pruebas empleando planchas de grano de resina y, más tarde, planchas tramadas (Koeman, 1972, 149; Ariza López, 1997, 146-148). En un principio, se aplicó en ediciones monocromas y, después, a partir de 1889, a ediciones policromas como el mapa del imperio austro-húngaro a escala 1:200.000 (Cubillo y Galbis, 1905; Kretschmer, 1997, 146-148).

La adopción del sistema del heliograbado en cobre permitía, tal como lo explicaban Cubillo y Galbis, abaratar el proceso de reproducción gráfica de los mapas e incrementar la productividad editorial. Así, según estos ingenieros geógrafos, a principios del siglo xx, en el litografiado de una hoja del 1:50.000 se empleaban 225 días de trabajo y se gastaban 1.944 pesetas, mientras que en el sistema del heliograbado en cobre era preciso dedicar tan solo 104 días de trabajo y gastar 829 pesetas (Cubillo, Galbis, 1905; Koeman, 1972, 150). La adopción del sistema del heliograbado en cobre presentaba, además, según estos ingenieros geógrafos, otras ventajas adicionales importantes respecto al sistema litográfico. En primer lugar, la utilización de la fotografía resultaba un sistema mucho más eficiente para la ampliación y reducción de los mapas que no el uso del pantógrafo, empleado en el sistema litográfico. Y, en segundo lugar, el almacenamiento de las placas matrices o planchas de cobre ocupaba 
bastante menos espacio que el de las piedras litográficas, cuya conservación ocasionaba problemas considerables.

El uso del heliograbado permitía que si lo que se quería imprimir era un mapa monocromo tan solo fuera necesario obtener una plancha de cobre. Ahora bien, si de lo que se trataba era de imprimir un mapa polícromo, como era el caso de las hojas del Mapa Topográfico de España a escala 1:50.000, entonces era preciso obtener tantas planchas de cobre como colores tenía este mapa.

El procedimiento para obtener la plancha de cobre era idéntico en ambos casos. El primer paso era conseguir un cliché o fotolito de muy buena calidad.

\section{FIGURA 4}

MINUTA O TELÓN DE LA HOJA N 419: VILLAFRANCA DEL PANADÉS, REALIZADA A ESCALA 1:25.000 EL UNO DE ABRIL DE 1925 Y FIRMADA POR EL INGENIERO ANTONIO RUBIO MARÍN Y EL TOPÓGRAFO LUIS PAREDES, ADSCRITOS AL NEGOCIADO DE PUBLICACIONES DEL INSTITUTO GEOGRÁFICO

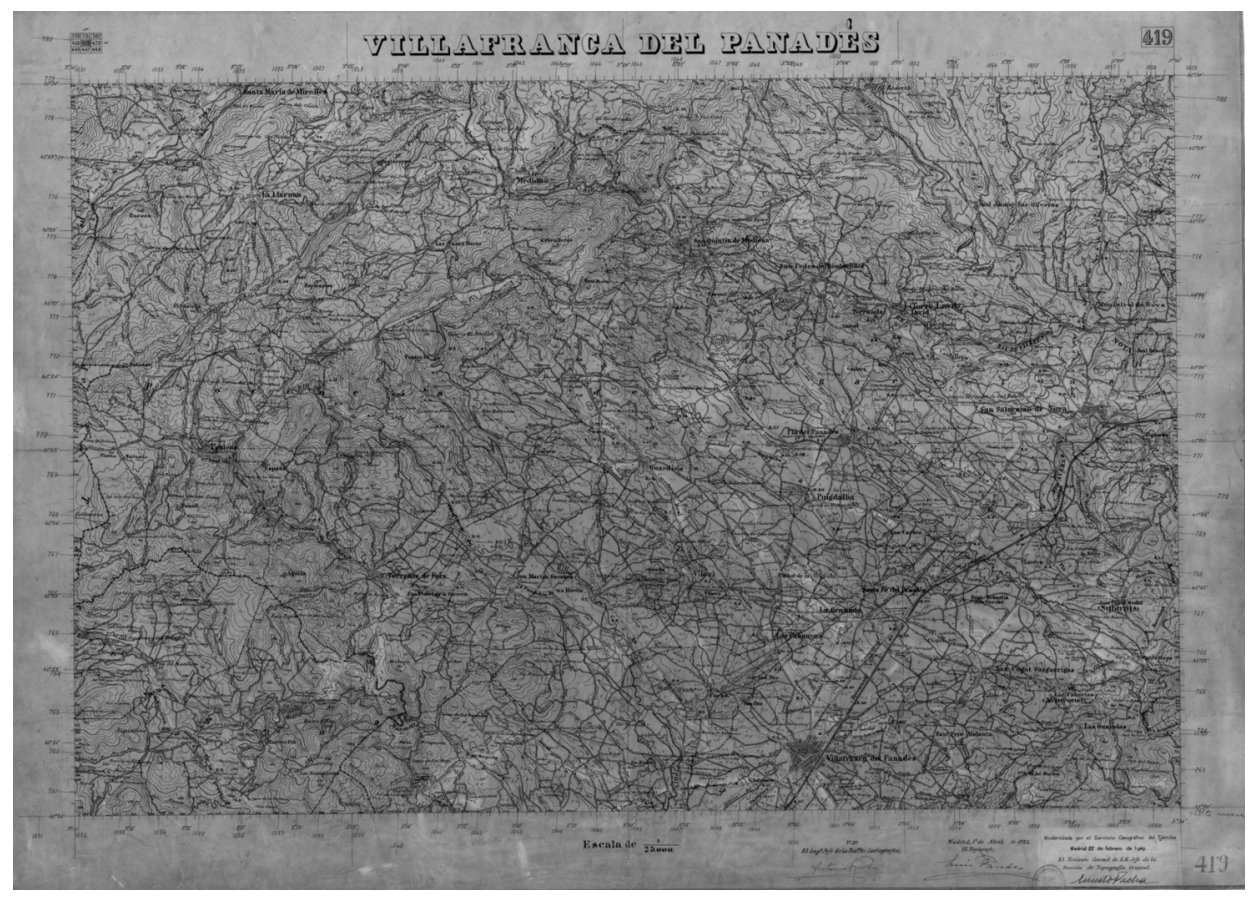

Fuente: Instituto Geográfico Nacional.

Estudios Geográficos, Vol. LXXVI, 278, pp. 235-263, enero-junio 2015 ISSN: 0014-1496, eISSN: 1988-8546, doi: 10.3989/estgeogr.201508 
Si se trataba de una reproducción monocroma este cliché se obtenía dibujando con pluma todos los elementos geográficos y cartográficos del mapa que se querían publicar y a una escala dos veces más grande que la del mapa que, finalmente, se imprimiría. En el caso de una reproducción polícroma ésta se conseguía realizando, de la misma manera, un fotolito diferente para cada uno de los colores empleados en la misma.

En el caso de las hojas del Mapa Topográfico de España de esta parte del proceso del heliograbado se encargaban los delineantes cartográficos. El primer paso que ejecutaban era dibujar a escala 1:25.000 la minuta o «telón» de la hoja que se pensaba imprimir a escala 1:50.000 (véase figura 4). Esta operación se efectuaba dibujando en una hoja, que acabaría convirtiéndose en la minuta, la información geográfica y cartográfica contenida en las planimetrías y topografías municipales que cubrían la hoja que se pensaba imprimir y que habían sido trazadas a escala 1:25.000 por miembros del Cuerpo de Topógra-

\section{FIGURA 5}

\section{LIMPIO EN ROJO DE LA HOJA No 419: VILLAFRANCA DEL PANADÉS}

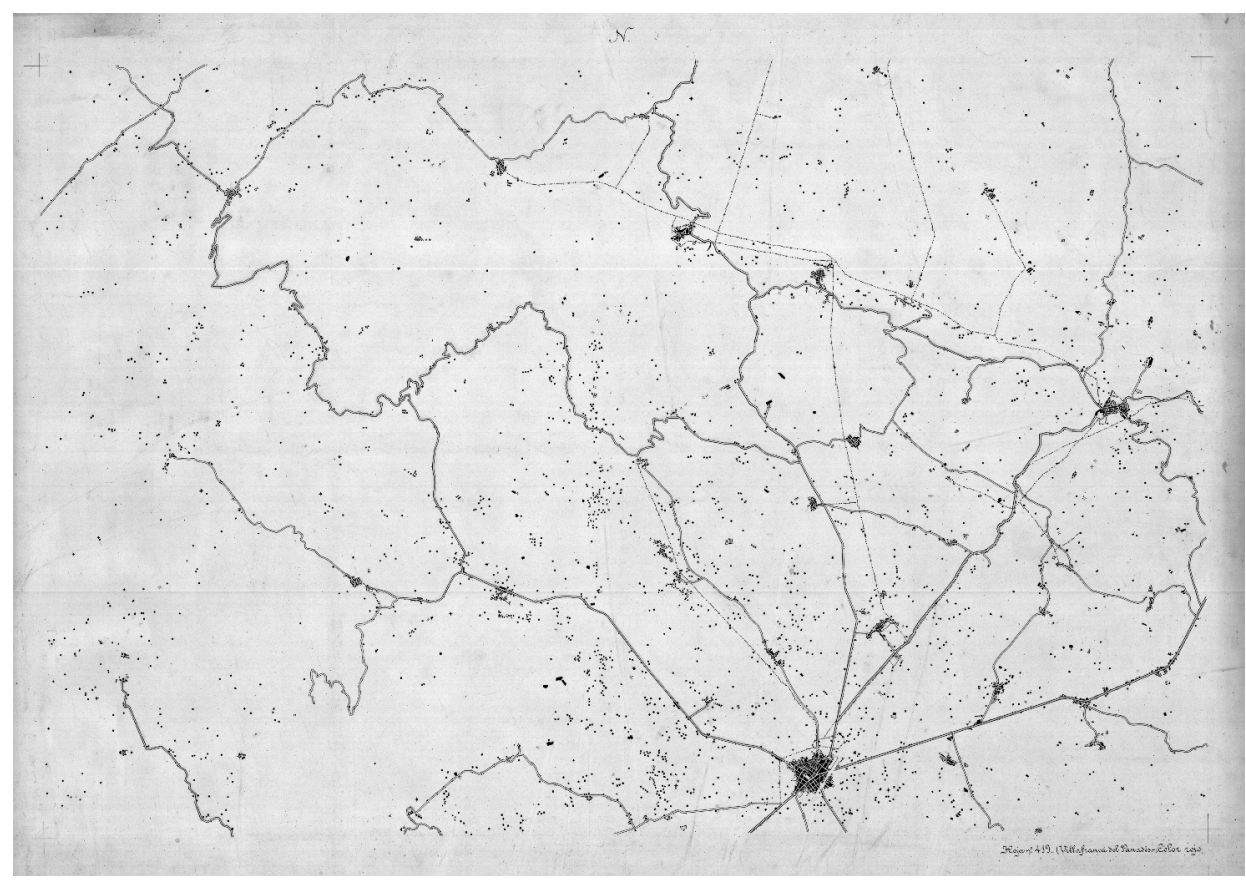

Fuente: Instituto Geográfico Nacional.

Estudios Geográficos, Vol. LXXVI, 278, pp. 235-263, enero-junio 2015

ISSN: 0014-1496, eISSN: 1988-8546, doi: 10.3989/estgeogr.201508 
fos. Sin embargo, no todas las minutas de las hojas del Mapa Topográfico de España a escala 1:50.000 se obtuvieron de esta manera, ya que muchas minutas fueron realizadas durante la década de 1920 y principios de la siguiente, por el Depósito de la Guerra a escala 1:20.000. Este hecho obligaba a los fotógrafos del Instituto Geográfico a realizar una primera reducción fotográfica a escala 1: 25.000 de estas minutas.

Una vez obtenidas las minutas a esta escala, tanto las elaboradas por el propio Instituto Geográfico como por el Depósito de la Guerra, se procedía a realizar el proceso de separación de colores, que consistía en la elaboración de cincos hojas llamadas «limpios». Un «limpio» para cada uno de los cinco colores empleados en la primera edición del Mapa Topográfico de España. En cada una de estas hojas especiales tan sólo estaban dibujados los elementos

FIGURA 6

MÁQUINA FOTOGRÁFICA DE LA EMPRESA HOHN U. HAHNE DE LEIPZIG, EMPLEADA POR EL INSTITUTO GEOGRÁFICO PARA LAS AMPLIACIONES Y REDUCCIONES DE LA ESCALA DE LAS MINUTAS Y DE LOS LIMPIOS

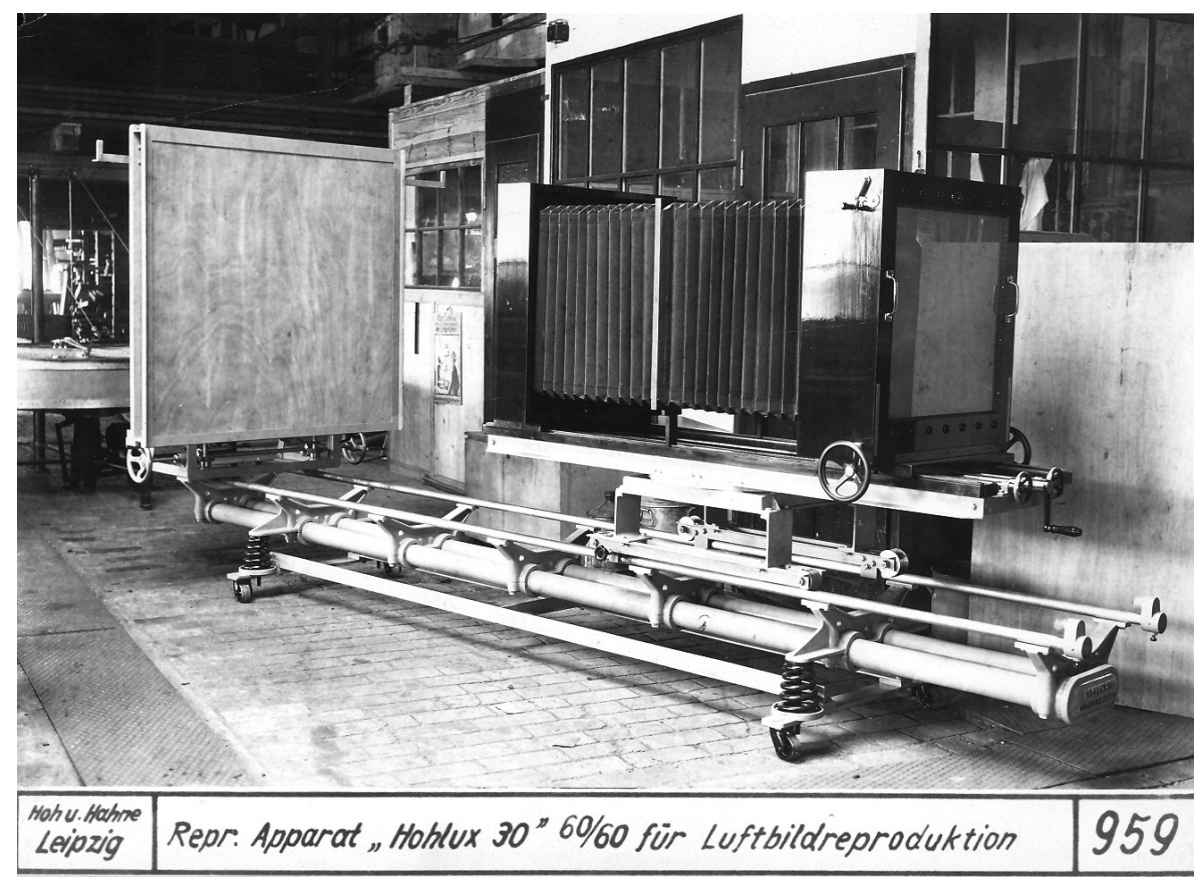

Fuente: Instituto Geográfico Nacional. 
geográficos y cartográficos relativos a un único color ya fuese este el negro, el siena, el azul, el rojo o el verde (véase figura 5). Después, se transferían los «limpios» a la Sección de Artes Gráficas, donde se llevaba a cabo una primera operación que consistía en la reducción fotográfica a escala 1:50.000 de estos «limpios», mediante la utilización de una cámara fotográfica especial de reproducción (véase figura 6).

A continuación, una vez obtenida la reducción fotográfica de cada «limpio» a escala 1:50.000, se reproducía el dibujo obtenido de forma fotográfica con la placa fotográfica invertida a fin de obtener un cliché directo y a la escala que se quería editarlo. Después, se llevaban a cabo toda una serie de operaciones para tratar la plancha de cobre (graneado y calentamiento), sobre la que se había de trasladar la imagen del cliché directo. Una vez hecho esto, se colocaba esta prueba positiva sobre la plancha de cobre previamente tratada y se procedía a disolver la parte de la plancha que no estaba impregnada por la luz y que era, por tanto, soluble.

Tras esta acción sólo quedaba la parte insoluble, que sustituía el dibujo reproducido y que estaba adherida a la plancha de cobre, de forma similar, a lo que sucede con las calcomanías. Después, una vez resueltos todos estos pasos, se conseguía, mediante el procedimiento de la galvanoplastia, una plancha de cobre de bastante consistencia, en la que había quedado grabado en relieve el dibujo trazado. El siguiente paso consistía en acerar la plancha de cobre, de manera que fuese más resistente al desgaste que ocasionaba el proceso de impresión y permitiese llevar a cabo tiradas mayores (Cubillo, Galbis, 1905; Namias, 1926). Por último, una vez obtenidas cinco planchas de cobre aceradas, una para cada uno de los colores empleados en la edición del Mapa Topográfico de España, se procedía a estampar la hoja que se quería publicar (véase figura 7).

La segunda técnica fotomecánica empleada, la fotolitografía en zinc, evolucionó con rapidez a principios del siglo xx gracias a dos innovaciones técnicas diferentes: la invención en 1901 del proceso de impresión de coloides bicromatados (chromium-gum) sobre planchas de zinc por el Dr. Strecker y la prensa offset que experimentó un gran desarrollo a partir de 1904 (Koeman, 1972, 151). El procedimiento fotolitográfico se adecuaba a una rotativa offset, que es una máquina de impresión planigráfica indirecta, en la que la imagen del fotolito reportada a la plancha de zinc no es impresa, de forma directa, sobre el papel, sino que es transferida, primero, a un tambor intermedio con una capa de caucho, que coge la tinta aplicada por la plancha y, después, la imprime en el papel (Ariza, 1999, 113). Tal como se ha indicado esta técnica 


\section{FIGURA 7}

\section{PRIMERA EDICIÓN DE LA HOJA Nº 419: VILLAFRANCA DEL PANADÉS, 1926}

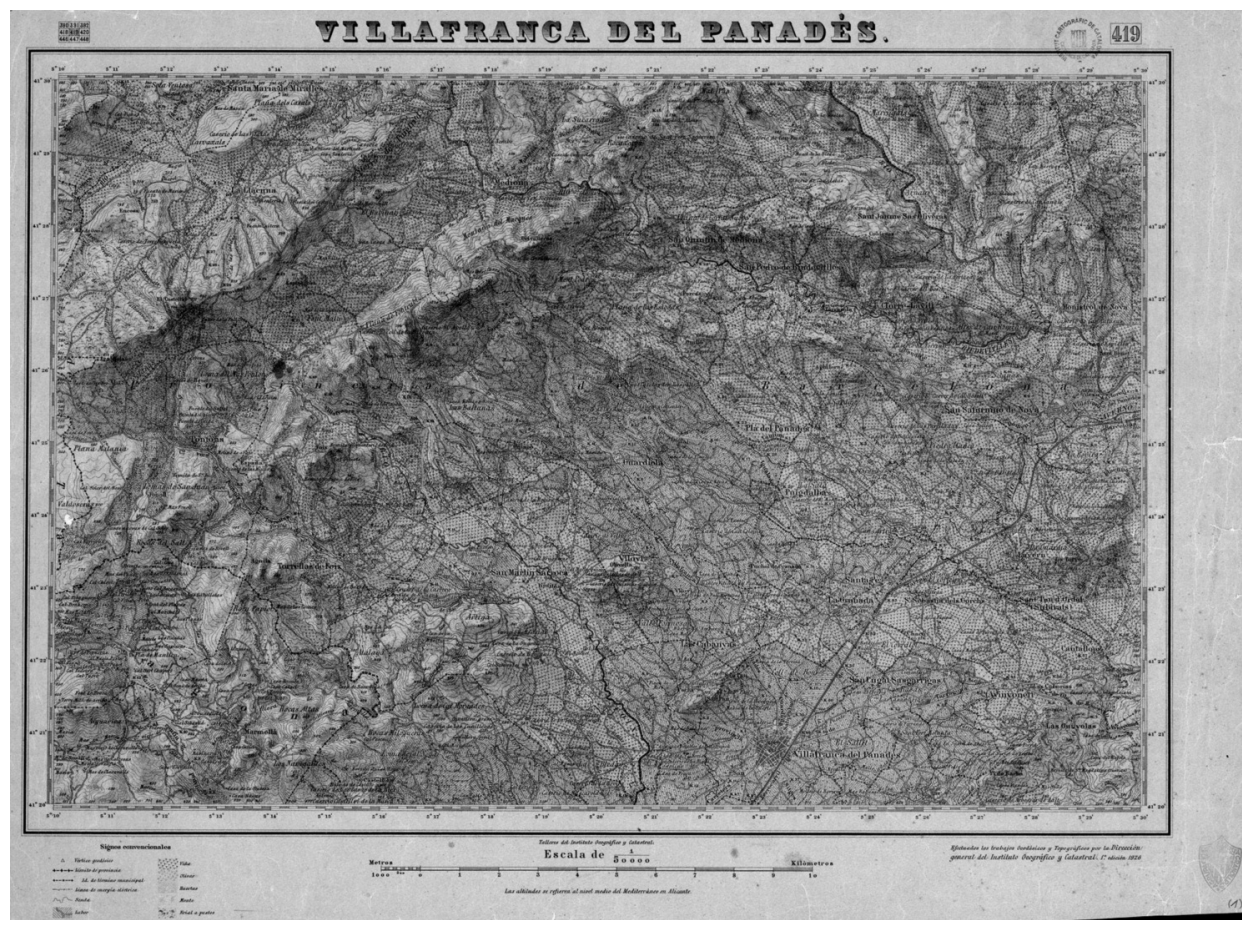

Fuente: Institut Cartogràfic i Geològic de Catalunya.

llegó al Instituto Geográfico siendo director general del Instituto Geográfico el oficial de Estado Mayor José Elola Gutiérrez (1859-1933).

La fotolitografía en zinc constituye una técnica de reproducción fotomecánica que difiere del heliograbado en cobre, básicamente, en el hecho de que, mientras ésta es una variación del procedimiento de impresión en hueco (calcografía), aquella constituye una variación del procedimiento de reproducción de tipo plano (litografía) (Ariza, 1999, 106-113). Así, en este caso la parte que se imprime no son las zonas huecas, sino la superficie plana de una plancha de zinc humedecida, en la que una parte de la misma está ocupada por una emulsión sobre la cual se ha depositado una cierta cantidad de tinta grasa. Las zonas de impresión constituyen los espacios de la plancha ocupadas por esta emulsión, en los que se ha transferido o reportado el cliché o fotolito 
con la imagen o dibujo que se desea imprimir. Si esta imagen o dibujo es polícroma es necesario realizar tantos fotolitos como colores contenga. Así, en el caso de las hojas del Mapa Topográfico de España era preciso hacer, al igual que sucedía con la técnica del heliograbado, cinco fotolitos. En este sentido, el proceso de elaboración de las minutas o telones, así como el de separación de colores y la obtención de los «limpios» era similar al efectuado en la técnica del heliograbado (figuras 4, 5, 6 y 7).

\section{LAS EDICIONES}

La primera hoja del Mapa Topográfico de España a escala 1:50.000 que se reprodujo mediante la técnica del heliograbado en cobre, la $\mathrm{n}^{\circ}$ 584: Mondéjar, fue impresa en 1915 (Urteaga, Nadal, 2001, 43). Al año siguiente se publicaron ya siete hojas mediante la aplicación de esta técnica. Sin embargo, fue en 1917, cuando se produjo el gran salto, pues se consiguieron imprimir ni más ni menos que 25 hojas. Atrás quedaban los largos años, en los que el sistema litográfico había constreñido el ritmo de edición del Mapa Topográfico de España a una media de cinco hojas por año Urteaga, Nadal, 2001, 43) (véase figura 1).

En la hoja $n^{\circ}$ 584: Mondéjar, impresa en 1915, se puede leer en la parte central del margen inferior de la misma la siguiente información: «Talleres del Instituto Geográfico y Estadístico. F. Noriega y J. Cabo de Guzmán dibujaron». Idéntica información puede leerse en tres de las hojas impresas en 1916: la $n^{\circ}$ 485: Valdepeñas de la Sierra, la $n^{\circ}$ 857: Valsequillo y la $n^{\circ}$ 1.037: Teba. Sin embargo, a partir de 1916, las hojas empezaron a llevar impresa en la misma parte de la hoja la siguiente información: «Talleres del Instituto Geográfico y Estadístico. Heliograbado en cobre». Una información, que se mantuvo en todas las hojas que se editaron hasta 1925 y que ponía de manifiesto no sólo la técnica de reproducción fotomecánica empleada, sino también su carácter anónimo e industrial. Después, a partir de 1926, aunque las hojas dejaron de indicar cuál era la técnica de reproducción cartográfica que se había utilizado en su impresión, éstas empezaron a imprimirse mediante el procedimiento de la fotolitografía en zinc.

Entre 1915 y 1956 se grabaron y estamparon mediante estas técnicas de reproducción fotomecánica 883 hojas de la primera edición del Mapa Topográfico de España (véase figura 1). Una cifra que nos indica que casi el 80 por ciento de las hojas de la primera edición se imprimieron con este sistema de reproducción cartográfica y que el ritmo de edición fue, por término medio, 
de 21,5 hojas por año. Este ritmo de edición no se mantuvo, sin embargo, de forma uniforme a lo largo de esos años, de manera que se pueden distinguir, a grandes rasgos, cinco fases de edición, que coinciden con importantes cambios técnicos, con circunstancias históricas determinadas o con variaciones en la política cartográfica. Por otro lado, fue también en 1915, cuando, gracias al gran incremento de la capacidad editorial que supuso la aplicación del heliograbado, se inició «de facto» la segunda edición de este mapa. Así, desde entonces hasta 1935, se imprimieron un total de 20 hojas de esta edición a un ritmo de edición de 8,5 hojas por año.

En relación a la primera edición, es preciso distinguir una fase inicial, que coincide con los años en que estuvo en práctica la técnica del heliograbado en cobre. Durante esta fase, que comprende los años 1915-1925, se imprimieron un total de 109 hojas con un ritmo medio de edición de 9,9 hojas por año. A continuación, a partir de la puesta en funcionamiento de la fotolitografía en zinc en 1926 se inició una nueva fase que se prolongará hasta el inicio de la Guerra Civil. Durante la misma se imprimieron un total de 298 hojas con un ritmo medio de edición de 27, 1 hojas por año. Un incremento que se debió, sin duda, a la aplicación de la nueva técnica de la fotolitografía en zinc y a la ampliación de los Talleres del Instituto Geográfico y que permitió triplicar el ritmo de la edición conseguido con la técnica del heliograbado.

Este buen ritmo de edición quedó, desgraciadamente, truncado en julio de 1936 con el estallido de la Guerra Civil. Las necesidades cartográficas de la guerra hicieron que el esfuerzo editorial del Instituto Geográfico estuviera dirigido, por entero, a publicar una Edición Especial de guerra del Mapa Topográfico de España a escala 1:50.000, de la que se imprimieron 401 hojas (Nadal, 2013, 91). De hecho, durante los dos años centrales de la contienda, 1937-1938, tan sólo se editó una hoja de la primera edición de este mapa, la $n^{\circ}$ 294: Manlleu, que se editó en abril de 1938. Este era un hecho ciertamente singular, ya que si bien esta hoja presenta todas las características propias de la primera edición, contiene además superpuesta una cuadrícula militar Lambert propia de la Edición Especial de guerra republicana.

En 1939, una vez concluida la guerra, se inició una nueva fase en la publicación de la primera edición que se prolongó hasta 1947 y que coincidió, en gran parte, con los años de la Segunda Guerra Mundial. Así, entre 1939 y 1947, se editaron un total de 320 hojas. Sin embargo, si de esta cifra descontamos las hojas impresas en el año 1939, en el que una buena parte del mismo estuvo todavía bajo los efectos de la Guerra Civil, el ritmo de edición fue durante estos años de 38,5 hojas impresas por año. Las razones que dieron lugar a un ligero incremento de la labor editorial respecto al período anterior a la 
guerra hay que buscarlas en el plan cartográfico, aprobado en julio de 1941, por los nuevos responsables del Instituto Geográfico y Catastral. Según este plan la primera edición del Mapa Topográfico de España debería quedar finalizada en un plazo máximo de diez años (Urteaga, Nadal, 2001, 92-94). Este objetivo resultó, sin embargo, imposible de cumplir por problemas de orden diverso como las constantes restricciones de energía eléctrica que afectaron al sistema productivo español durante los primeros años de la postguerra. Pero, también por la propia capacidad productiva de los Talleres del Instituto Geográfico y Catastral, ya que, según un informe elaborado, en 1948, por el Consejo Superior Geográfico, estaba limitada entonces a una impresión máxima de 60 hojas por año (Urteaga, Nadal, 2001, 94).

A partir de 1948, se entró ya en la última fase que se prolongó hasta 1956. Durante la misma tuvo lugar un acusado descenso del ritmo editorial, que quedó reducido a la mitad del que se había mantenido en la fase precedente. Así, durante estos años se imprimieron un total de 155 hojas a un ritmo medio de edición de 19,3 hojas impresas por año. Esta caída tan pronunciada del ritmo de edición fue debida, en gran medida, a los nuevos imperativos geoestratégicos de la Guerra Fría. Unos imperativos que cambiaron el orden de prioridades cartográficas del Instituto Geográfico. Así, en 1947, en el marco de un progresivo acercamiento político entre los gobiernos norteamericano y español, el Consejo Superior Geográfico dio orden de revisar un gran bloque de 173 hojas del Mapa Topográfico de España correspondiente a la zona fronteriza de los Pirineos y del valle del Ebro (Urteaga, Nadal, Muro, 2002, 154). Se trataba de un extenso territorio de alto valor geoestratégico en caso de un eventual conflicto armado entre el bloque occidental y la Unión Soviética, que el mismo Army Map Service norteamericano se ocupó de cartografiar, entre 1950 y 1951, realizando una edición especial de la Serie M781 del Mapa Topográfico de España a escala 1:50.000 (Urteaga, Nadal, Muro, 164-166).

Como consecuencia de ello, el objetivo establecido en el plan cartográfico de 1941 de terminar la primera edición del Mapa Topográfico de España en un plazo de diez años dejó de ser prioritario. Así, entre 1948 y 1953, se editaron 69 hojas de la segunda edición del Mapa Topográfico de España a escala 1:50.000 relativas a la mencionada «zona Nordeste» (Urteaga, Muro, Nadal, 2002, 160-163). Por otro lado, durante el quinquenio 1950-1954 se publicaron un total de 236 hojas de la segunda y tercera edición del Mapa Topográfico de España por tan sólo 93 de la primera edición (Nadal, Urtea ga, 1990, 71).

Después, en 1956, cuando aún no se había iniciado la impresión de las hojas de la primera edición correspondientes al archipiélago balear, el Instituto 
Geográfico adquirió al Service Topographique Féderal de Suiza la patente de un nuevo sistema de reproducción fotomecánica: el esgrafiado en vidrio (Núñez de las Cuevas, 1964, 1). Se iniciaba entonces el último capítulo de la primera edición del Mapa Topográfico de España, que afectó a las 80 hojas que todavía no habían sido publicadas y que no finalizó hasta 1968.

\section{CONCLUSIONES}

A principios del siglo xx, la edición del Mapa Topográfico de España a escala 1:50.000 se encontraba en una situación crítica a causa de la adopción en 1875 de la litografía o grabado en piedra como sistema de reproducción cartográfica. Este sistema permitía la estampación policroma de los mapas y posibilitaba un gran desarrollo de la cartografía temática. Sin embargo, resultaba muy caro y lento. Así, en 1900, después de veinticinco años de aplicación del mismo, tan sólo se habían conseguido imprimir 118 hojas de las 1.106 que componía la primera edición del Mapa Topográfico de España. Esto significaba que el ritmo medio de edición era de 4,7 hojas por año y que, si no se producía algún tipo de cambio, se tardarían 210 años en concluirla.

A fin de resolver esta situación, en 1904, la dirección del Instituto Geográfico comisionó a dos ingenieros geógrafos, Luis Cubillo Muro y José Galbis Rodríguez, para que realizasen un viaje de estudio a diversos centros cartográficos europeos de la época a fin de recabar información sobre los sistemas de reproducción cartográficos empleados. El resultado de sus indagaciones quedó expuesto en una memoria presentada en 1905 y en la que se defendía la implantación de un sistema de reproducción cartográfica denominada heliograbado en cobre, aplicada con éxito en el K.u.K. Militär-Geographisches Institut de Viena desde principios de la década de 1870.

La propuesta fue aceptada, iniciándose, a partir de entonces, un importante proceso de cambio tecnológico. Así, entre 1910 y 1924, se organizó el Negociado de Publicaciones en tres secciones diferentes: la de Dibujo y Cálculo Planimétrico, la de Cartografía y la de Artes Gráficas, de la que dependían los Talleres del Instituto Geográfico. Por otro lado, se enviaron a algunos de sus empleados al extranjero a aprender las técnicas del heliograbado. Además, se impulsó la creación, en 1922, de dos nuevos cuerpos técnicos del Instituto Geográfico: el Cuerpo de Oficiales de Artes Gráficas y el de Ayudantes de Artes Gráficas. Este proceso de cambio recibió un nuevo impulso durante la segunda mitad de la década de 1920, cuando se implantó otra técnica de reproducción fotomecánica, la fotolitografía en zinc, y se destinaron cuantio- 
sos recursos económicos a la construcción de un moderno edificio industrial destinado a los Talleres del Instituto Geográfico, que por aquel entonces se habían convertido en el principal centro de edición de mapas de España.

Fruto de estos cambios, en 1915, se imprimió la primera hoja del Mapa Topográfico de España mediante la técnica del heliograbado en cobre. Una técnica que estuvo en uso en la edición de este mapa hasta 1926, año en que fue reemplazada por la de la fotolitografía en zinc que estuvo vigente hasta 1956. Durante esos años se publicaron 883 hojas de la primera edición del Mapa Topográfico de España, una cifra que indica que casi el 80 por ciento de las hojas de esta edición se imprimieron con estas nuevas técnicas de reproducción cartográfica que permitieron quintuplicar el ritmo medio de edición. Este ritmo no siguió, sin embargo, una evolución uniforme, viéndose muy afectada tanto por los importantes cambios políticos que vivió la sociedad española durante esos años como por la conflictiva situación internacional.

Fecha de recepción: 27 de diciembre de 2013.

Fecha de aceptación: 1 de diciembre de 2014.

\section{BiBLIOGRAFIA}

Anduaga Egaña, A. (2010): Geofísica, economía y sociedad en la España contemporánea. Madrid, Consejo Superior de Investigaciones Científicas, 379 pp.

Ariza López, F. J. (1999): Reproducción cartográfica. Jaén, Universidad de Jaén, 252 pp. Burgueño, J. (2010): "Mapas para una guerra. El Plano Director a escala 1:25.000 (1937-1939)". Ería. Revista cuatrimestral de geografía, 83, pp. 261-289.

Cook, K. S. (2002): "The historical role of photomechanical techniques in map production". Cartography and Geographic Information Science, 9/1, pp. 137-154.

Fontbona, F. (1988): "La ilustración gráfica. Las técnicas fotomecánicas", en J. Carrete (ed.): El grabado en España (siglos XIX-XX). Summa Artis. Historia general del Arte. vol. XXXII. Madrid, Espasa-Calpe, pp. 429-610.

Galbis Rodríguez, J. (1950): "Testamento laboral del ingeniero geógrafo José Galbis Rodríguez", en Mario Ruiz Morales (ed.): El ingeniero geógrafo José Galbis al servicio de la meteorología. Madrid. Instituto Geográfico Nacional, 2005, pp. 1-121.

Galiana Matesanz, $\mathrm{M}^{\mathrm{a}}$ T. (2010): Catálogo de planos y proyectos de arquitectura del Archivo-Biblioteca de la Real Academia de Bellas Artes de San Fernando. Madrid, Real Academia de Bellas Artes de San Fernando.

Gastardi, E. (1934): Informe en español y francés sobre los trabajos topográficos, foto-topográficos y cartográficos ejecutados por el Instituto Geográfico y Catastral durante los años 1931, 1932 y 1933. Presentado al Congreso Internacional de Geografía. Var- 
sovia, agosto 1934. Madrid, Talleres del Instituto Geográfico y Catastral, 12 pp.+8 láminas.

Harley, J. B. (1979): "The Ordnance Survey and land-use mapping. Parish Books of Reference and the County Series 1:2 500 maps, 1855-1918”. Historical Geography Research Group: Research paper Series, 2.

Harley, J. B. (1997): "El mapa com a biografia: reflexions entorn del full 'Newton Abbot, Devonshire CIX, SE' del mapa a sis polzades de l'Ordnance Survey”. Treballs de la Societat Catalana de Geografia, 45, pp. 247-253.

Heras Molinos, A. de las (2009): Aspectos cartográficos de la Guerra Civil española (1936-1939). Madrid, Instituto Geográfico Nacional, 428 pp.

Huguenin, M. (1948): Historique de la nouvelle carte de France. París, Imprimerie de l'IGN.

Instituto Geográfico y Estadístico [1875]: Signos convencionales. Madrid, Litografía del Instituto Geográfico y Estadístico.

Instituto Geográfico y Estadístico (1914): Estado de los trabajos geográficos en 1913. Madrid, Talleres del Instituto Geográfico y Estadístico.

Koeman, C. (1972): "The application of photography to map printing and the transition to ofsset lithography", en David Woodward (ed.): Five Centuries of Map Printing, Chicago, The University of Chicago Press, pp. 137-155.

Kretschmer, I. (1997): "The development of Austrian cartography. Cartographic representation of Austrian territorios", en Institut Cartogràfic de Catalunya: La cartografia dels països de parla alemanya: Alemanya, Austria i Suïssa. Barcelona, Institut Cartogràfic de Catalunya, pp. 121-176.

Martín López, J. M. (2001): Cartógrafos españoles. Madrid, Instituto Geográfico Nacional, $319 \mathrm{pp}$.

Martínez, J. A. (2000): "La Segunda República (1931-1936)", en Ángel Bahamonde (coord.): Historia de España Siglo xx, 1875-1939. Madrid, Cátedra, pp. 539-636.

Mier Miura, E. (1909): "Reseña de los trabajos de los Ingenieros del Ejército en el Instituto Geográfico”. Memorial de Ingenieros del Ejército, cuarta época, XXVI, pp. 265-281.

Monmonier, M. S. (1985): Technological transition in cartography. Wisconsin, University of Wisconsin, $282 \mathrm{pp}$.

Nadal, F. y Urteaga, L. (1990): "Cartografía y Estado. Los mapas topográficos nacionales y la estadística territorial en el siglo XIX". Geo Crítica, 88, pp. 7-93.

Nadal, F. y Urteaga, L. (2012): "La primera edició del Mapa Topogràfic d'Espanya a escala 1:50 000. Fulls relatius a Catalunya (1910-1945)", en Institut Cartogràfic de Catalunya (ed.): Atles topogràfic-històric de Catalunya 1:50 000. Barcelona, Institut Cartogràfic de Catalunya, Barcelona, pp. 13-64.

Nadal, F. y Urteaga, L. (eds.) (2013): Mapas y cartógrafos en la Guerra Civil española (1936-1939). Madrid, Instituto Geográfico Nacional, 290 pp.

Namias, R. (1920): Antonio Revenga (trad.): Procedimientos de ilustración gráfica: fotograbado, fototipia, fotolitografia, heliograbado, rotocalcografía. Madrid, RaillyBailliere, $319 \mathrm{pp}$. 
Núñez de las Cuevas, R. (1964): Nouvelles techniques utilisées pour la confection de la Carte Nationale d'Espagne au 1/50.000. Madrid, Instituto Geográfico y Catastral, $11 \mathrm{pp}$.

Payo Subiza, G. y Gómez-Menor, R. (1998): Historia del Observatorio Geofísico de Toledo. Madrid, Instituto Geográfico Nacional, 221 pp.

Ruiz Morales, M. (2003): Los Ingenieros Geógrafos. Origen y creación del cuerpo. Madrid, Instituto Geográfico Nacional. 286 pp.

Sanz, E. (2010): "Biografía de los artistas", en C. Priego (dir.): Arquitectura madrileña de los siglos XIX y XX. Madrid. Museo de Historia de Madrid, pp. 193-198.

Uriol Duties, F. (1930): État actuel de la carte nationale. Madrid, Talleres del Instituto Geográfico y Catastral, 5 pp.+2 mapas.

Urteaga, L. y Nadal, F. (2001): Las series del mapa topográfico de España a escala 1:50.000. Madrid, Instituto Geográfico Nacional, 397 pp.

Urteaga, L., Nadal, F. y Muro, J. I. (2002): "Un capítulo en la formación del mapa topográfico nacional a escala 1:50.000: el plan de modernización de la "zona Nordeste" (1947-1953)". Treballs de la Societat Catalana de Geografia, 53-54, pp. 153-173.

Wallis, H. y Robinson, A. H. (eds.) (1987): Cartographical Innovations. An International Handboock of Mapping Terms to 1900. [Tring], Map Collector Publications \& International Cartographic Association.

\section{RESUMEN}

A mediados del siglo xx la Sección de Cartografía y Publicaciones del Instituto Geográfico constituía la principal empresa editora de mapas de España. El proceso que daría lugar a este hecho se inició en 1905, cuando se decidió sustituir el sistema de reproducción litográfico, adoptado en 1875 para el grabado e impresión de las hojas del Mapa Topográfico de España a escala 1:50.000 por otro de tipo fotomecánico. En 1915 se publicó la primera hoja de este mapa mediante la técnica del heliograbado en cobre y en 1926 se implantó otra técnica de reproducción fotomecánica, la fotolitografía en zinc, que estuvo vigente hasta 1956. Ambos cambios dieron lugar, durante el primer tercio del siglo $\mathrm{xx}$, a diversas reformas organizativas, a la formación de dos cuerpos técnicos y a importantes inversiones de tipo material. Como consecuencia de ello, entre 1915 y 1956 se grabaron y estamparon 883 de las 1.106 hojas que formaban la primera edición de este mapa.

Palabras Clave: Mapa Topográfico de España; edición cartográfica; heliograbado; fotolitografía; Instituto Geográfico Nacional.

\section{ABSTRACT}

In the middle of the twentieth century the Cartographic and Publications Section of the Instituto Geográfico was the main publisher of maps of Spain. The process that would lead this fact began in 1905, when was decided to replace the lithographic re- 
production of maps system, adopted en 1875 for engraving and printing the sheets of the Topographical Map of Spain at scale 1:50,000 scale, by a photomechanical process of map reproduction. In 1915 was published the first sheet of this map engraved with copper heliogravure and in 1926 was implemented a new technique of photomechanical reproduction, the zinc photolithography, that was in operation until 1956. These changes resulted, during the first third of the twentieth century, in several organizational reforms, the formation of two technical bodies and one great investment in technical material and buildings. As consequence of it, between 1915 and 1956 were recorded and stamped 883 of the 1,106 sheets that formed the first edition of this map.

KEY WORDS: Topographic Map of Spain; map printing; heliogravure; photolithography; Instituto Geográfico Nacional.

\section{RÉSUMÉ}

A la mi-vingitième siècle la Section de cartographie et publications de l'Instituto Geográfico était le principal centre éditeur de cartes de l'Espagne. Le processus qui mènerait à ce fait commencé en 1905, quand on á décide de remplacer le système de reproduction lithographique, adoptée en 1875 pour la gravure et l'impression des feuilles de la Carte topographique de l'Espagne á l'échelle $1: 50$ 000, pour un système de reproduction photomécanique. En 1915 a été publiée la première feuille de cette carte par la technique de l'heliogravure et l'année 1926 a été mais en œuvre une nouvelle technique de reproduction photomécanique, la photolitographie sur zinc, qui était en vigueur jusqu'en 1956. Ces changements ont entraîné, dans le premier tiers du vingtiéme siècle, un certain nombre de réformes organisationelles, la formation de deux corps techniques et a un investissement important en biens d'équipement. En conséquence, entre 1915 et 1956 ont été gravées et imprimées 883 des 1.1106 feuilles qui constituent la première édition de cette carte.

Mots ClÉs: Carte topographique de l'Espagne; édition cartographique; héliogravure; photolitographie; Instituto Geográfico Nacional. 